\title{
On the Structure of Cross-Conjugated 2,3-Diphenylbutadiene
}

\author{
Cornelis A. van Walree, ${ }^{*[a]}$ Bas C. van der Wiel, ${ }^{[a]}$ Leonardus W. Jenneskens, ${ }^{[a]}$ \\ Martin Lutz, ${ }^{[b]}$ Anthony L. Spek, ${ }^{[b]}$ Remco W. A. Havenith, ${ }^{[c]}$ and Joop H. van Lenthe ${ }^{[c]}$
}

Keywords: Conformation analysis / ab initio calculations / Conjugation / Hyperconjugation

The structure of the cross-conjugated compound 2,3-diphenylbutadiene was investigated by single-crystal X-ray diffraction and computational methods. In the crystal structure the central butadiene fragment adopts an s-gauche geometry $\left[-55.6(2)^{\circ}\right.$ torsion angle $\phi$ around the essential single bond], whereas the styrene moieties are close to planarity. MP2/6-311G* calculations show that the s-gauche conformation represents the global minimum along the $\phi$ coordinate, but also revealed the existence of an s-trans local minimum.
While the crystal structure seems to reflect dominance of styrene-like conjugation, the $\mathrm{MP} 2 / 6-311 \mathrm{G}^{*}$ calculations indicate that conjugation in both the styrene and butadiene $\pi$ systems is important. An NBO orbital deletion study shows that the structure is primarily determined by (hyper)conjugation and that steric effects play a minor role.

(@) Wiley-VCH Verlag GmbH \& Co. KGaA, 69451 Weinheim, Germany, 2007)

\section{Introduction}

Molecules and polymers with a $\pi$-conjugated bonding motif play a central role in the development of organic materials with advanced optic, electronic or electro-optic functions. Their properties depend strongly on the type of unsaturated units present (which can be double bonds, triple bonds or various kinds of aromatic moieties), but another factor of interest is the topology in which the unsaturated building blocks are connected. These are usually arranged in a linear fashion, but also a branched architecture is possible. ${ }^{[1-7]}$ In branched $\pi$-systems, which are also referred to as cross-conjugated systems, ${ }^{[8,9]}$ several linear $\pi$-conjugation paths are present. From a fundamental point of view it is of interest to assess which conjugation path dominates in a given cross-conjugated compound, and by which factors this is controlled. Knowledge of these and other properties of branched $\pi$-systems is important for the rational design of 2-dimensional conjugated systems. ${ }^{[10]}$ These hold a promise as advanced switching and conducting systems, ${ }^{[3,11]}$ while radical cations derived from cross-conjugated systems may form the foundation of high-spin magnetic materials. $^{[12-14]}$

A fundamental type of branched $\pi$-system is presented by 2,3-diphenylbutadiene (1). Photoinduced charge separa-

[a] Organic Chemistry and Catalysis, Utrecht University, Padualaan 8, $3584 \mathrm{CH}$ Utrecht, The Netherlands E-mail: c.a.vanwalree@chem.uu.nl

[b] Bijvoet Center for Biomolecular Research, Crystal and Structural Chemistry, Utrecht University,

Padualaan 8, $3584 \mathrm{CH}$ Utrecht, The Netherlands

[c] Theoretical Chemistry Group, Utrecht University, Padualaan 8, $3584 \mathrm{CH}$ Utrecht, The Netherlands

Supporting information for this article is available on the WWW under http://www.eurjoc.org or from the author. tion in a 2,3-diphenylbutadiene of which the phenyl groups were functionalized with electron donor-acceptor groups has been demonstrated, showing that charges can be transported over this cross-conjugated $\pi$-system. ${ }^{[15]}$ In 2,3-diphenylbutadiene three potential linear $\pi$-paths, viz. a 1,3butadiene subsystem and two styrene subsystems, are distinguished (Figure 1, a). This brings about that 1 can be regarded as a diphenyl-substituted butadiene, as $\alpha, \alpha$-bistyryl, or as somewhere in between these extremes. Which linear conjugation path prevails depends strongly on the dihedral angles between the different unsaturated moieties, and the other way around. It is known from work on related branched $\pi$-compounds such as dendralenes ${ }^{[1,16]}$ and phenylenevinylidene oligomers ${ }^{[5]}$ that steric interactions have a large impact on the structure of these compounds. In $\mathbf{1}$, twisting can occur along the essential single bond between the double bonds $(\phi)$ or along the single bonds which connect the phenyl groups to the double bond $(\theta$, Figure 1, b). When conjugation in the butadiene subsystem dominates, rotation will occur along $\theta$. Behavior as two $\alpha$-bonded styrenes will be reflected by rotation along $\phi$.

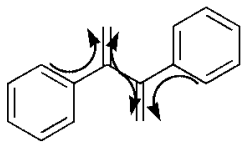

a b

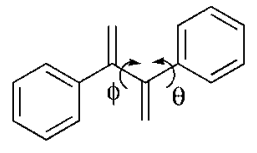

Figure 1. Possible conjugation paths (a) and designation of torsion angles (b) in 2,3-diphenylbutadiene $\mathbf{1}$.

In this contribution the molecular structure of 2,3-diphenylbutadiene is reported and interpreted in terms of conjugation phenomena and steric interactions. This is 
done by single-crystal X-ray diffraction, MP2/6-311G* structural calculations and a natural bond orbital (NBO) analysis.

\section{Results and Discussion}

\section{Single Crystal X-ray Structure}

To our surprise, the single-crystal X-ray structure of the relatively simple compound $\mathbf{1}$ has, until recently, not been published. The reason might be that, as we reported earlier, the crystal structure is subject to reticular pseudomerohedral twinning. ${ }^{[17]}$ The molecular structure is depicted in Figure 2, while important bond lengths and torsion angles are compiled in Tables 1 and 2, respectively. In the pseudo $C_{2}$ symmetric structure the compound adopts a butterfly-like geometry with a face-to-face like arrangement of the phenyl groups. The angle between the normals to the phenyl groups is $73.10(8)^{\circ}$. A striking feature is that the $\mathrm{C} 11-\mathrm{C} 12-$ $\mathrm{C} 22-\mathrm{C} 21$ torsion angle $\phi$ is $-55.6(2)^{\circ}$. Thus, the butadiene subsystem is in a gauche conformation and far from planar. By analogy with butadiene, ${ }^{[18,19]}$ one would be inclined to think that 1 adopts an s-trans geometry. Torsion angles around the $\mathrm{C} 12-\mathrm{C} 13$ and $\mathrm{C} 22-\mathrm{C} 23$ single bonds all lie in the range $-15.6(2)$ to $-19.3(3)^{\circ}$ or $160.50(18)$ to $164.92(15)^{\circ}$. The near-planar geometry around these bonds corresponds to the situation in styrene, for which torsion angles of the same order of magnitude have been reported. ${ }^{[18,20]}$ Both the butadiene and the styrene substructures suggest that $\mathbf{1}$ should be regarded as being composed of two $\alpha, \alpha$-linked styrene units, rather than as a disubstituted butadiene. This is supported by the C12-C22 bond length of 1.492(2) $\AA$. Even for a $\mathrm{C}\left(\mathrm{sp}^{2}\right)-\mathrm{C}\left(\mathrm{sp}^{2}\right)$ single bond in a twisted system (i.e., with torsion angles larger than $20^{\circ}$; the average length of such bonds is $1.478(12) \AA]^{[21]}$ this is long. Somewhat in disagreement with the above picture, the lengths of the $\mathrm{C} 12-\mathrm{C} 13$ and $\mathrm{C} 22-\mathrm{C} 23$ single bonds do not match those in other planar styrene moieties and are quite large for a $\mathrm{C}\left(\mathrm{sp}^{2}\right)-\mathrm{C}($ aryl $)$ single bond. The average length of $\mathrm{C}\left(\mathrm{sp}^{2}\right)-$ $\mathrm{C}\left(\right.$ aryl) bonds is $1.470(15) \AA .{ }^{[21]}$ The $\mathrm{C} 11-\mathrm{C} 12$ and $\mathrm{C} 21-$ C22 distances do not lend themselves to discriminate between butadiene or styrene conjugation, as they do not deviate from the double bond length in both butadienes $(1.330(14) \AA]$ and phenyl-substituted alkenes (1.339(11) ^]. ${ }^{[21]}$ No sign of bond length alternation is detected within the phenyl groups. It is known that bond length alternation phenomena are not particularly pronounced in cross-conjugated compounds. ${ }^{[22]}$

Short intramolecular contacts between the atoms or pair of atoms $\mathrm{C} 11 / \mathrm{H} 11$ and $\mathrm{C} 18 / \mathrm{H} 18, \mathrm{C} 21 / \mathrm{H} 21$ and $\mathrm{C} 28 / \mathrm{H} 28$, $\mathrm{C} 12$ and $\mathrm{H} 24$, and $\mathrm{C} 22$ and $\mathrm{H} 14$ are observed. This suggests that the region where the phenyl groups are linked to the butadiene moiety is crowded, and this may well be responsible for the long C12-C13 and C22-C23 bonds. Steric congestion in the butadiene moiety itself does not occur. This can be taken as another indication that conjugation within the butadiene moiety is more readily disrupted than conjugation within the styrene moieties.

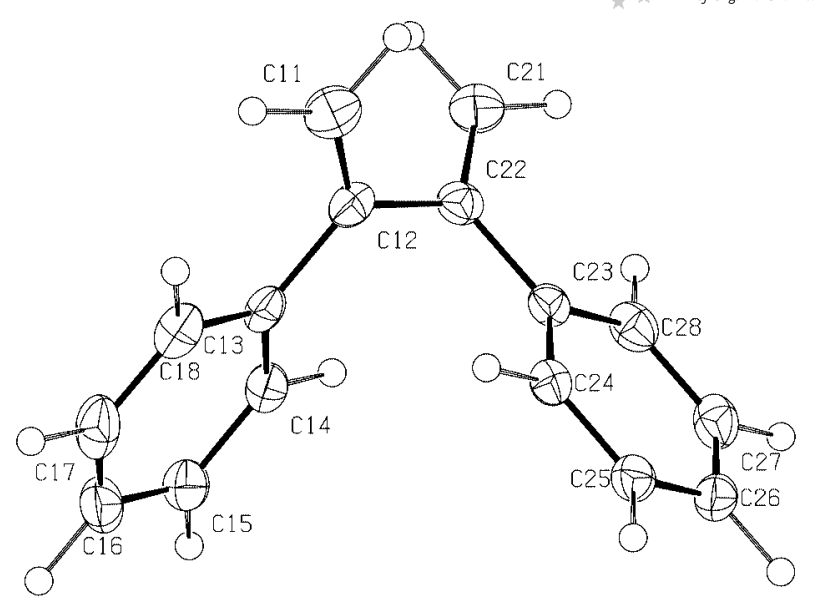

Figure 2. Displacement ellipsoid plot of the 2,3-diphenylbutadiene crystal structure, drawn at the $50 \%$ probability level, and adopted numbering scheme.

Table 1. C-C bond lengths $[\AA]$ in the crystal structure of $\mathbf{1}$, along with bond lengths in the MP2/6-311G* calculated s-gauche and $s$ trans minima ( $C_{2}$ symmetry).

\begin{tabular}{llllll}
\hline Bond & X-ray & s-gauche & s-trans & Bond & X-ray \\
\hline C11-C12 & $1.329(3)$ & 1.350 & 1.352 & C21-C22 & $1.335(3)$ \\
C12-C13 & $1.491(2)$ & 1.480 & 1.483 & C22-C23 & $1.486(2)$ \\
C12-C22 & $1.492(2)$ & 1.484 & 1.480 & & \\
C13-C14 & $1.393(2)$ & 1.404 & 1.403 & C23-C24 & $1.397(2)$ \\
C13-C18 & $1.397(3)$ & 1.403 & 1.404 & C23-C28 & $1.399(3)$ \\
C14-C15 & $1.391(2)$ & 1.395 & 1.397 & C24-C25 & $1.390(2)$ \\
C15-C16 & $1.386(3)$ & 1.398 & 1.397 & C25-C26 & $1.381(3)$ \\
C16-C17 & $1.377(3)$ & 1.397 & 1.399 & C26-C27 & $1.381(3)$ \\
C17-C18 & $1.383(3)$ & 1.396 & 1.395 & C27-C28 & $1.380(2)$ \\
\hline
\end{tabular}

Table 2. Selected torsion angles in the crystal structure of $\mathbf{1}$.

\begin{tabular}{llll}
\hline C11-C12-C13-C14 & $162.49(18)$ & C13-C12-C22-C21 & $122.5(2)$ \\
C11-C12-C13-C18 & $-17.0(3)$ & C13-C12-C22-C23 & $-59.6(2)$ \\
C22-C12-C13-C14 & $-15.6(2)$ & C12-C22-C23-C24 & $-17.3(2)$ \\
C22-C12-C13-C18 & $164.92(15)$ & C12-C22-C23-C28 & $162.89(15)$ \\
C11-C12-C22-C21 & $-55.6(2)$ & C21-C22-C23-C24 & $160.50(18)$ \\
C11-C12-C22-C23 & $122.3(2)$ & C21-C22-C23-C28 & $-19.3(3)$ \\
\hline
\end{tabular}

\section{Structural Calculations}

To get a deeper understanding of its structure, 1 was subjected to MP2/6-311G* calculations. A free optimization in the $\mathrm{C}_{2}$ point group gave an s-gauche structure with $\phi=48.7^{\circ}$ and $\theta=37.3^{\circ}$ (Figure 3) at an energy of -616.584103 a.u. $\left(-386912.42 \mathrm{kcal} \mathrm{mol}^{-1}\right)$. As $\phi$ is close to the angle found in the crystal, the calculated structure looks similar to the Xray structure. However, since the phenyl- $\mathrm{C}=\mathrm{C}$ torsion angle $\theta$ is $37.3^{\circ}$, twisting about the $\mathrm{C} 12-\mathrm{C} 13$ bond is much more pronounced than in the crystal so that the calculated structure reflects less styrene conjugation than the geometry in the solid state. As can be seen in Table 1, the MP2 lengths of the single bonds are on the short side, while the double bonds are a fraction too long. This indicates that MP2 tends to overestimate the conjugation to some extent. 

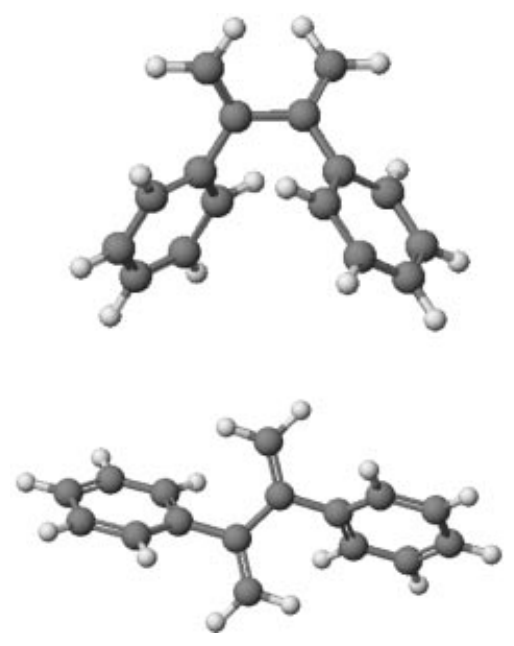

Figure 3. MP2/6-311G* calculated s-gauche (top) and s-trans (bottom) minima of $\mathbf{1}$.

Also, the energy of $\mathbf{1}$ as a function of rotation along the $\mathrm{C} 12-\mathrm{C} 22$ bond was evaluated. The $\mathrm{C} 11-\mathrm{C} 12-\mathrm{C} 22-\mathrm{C} 21$ torsion angle $\phi$ was varied in $15^{\circ}$ steps; at each point all other coordinates were optimized within the $\mathrm{C}_{2}$ point group. The only other coordinates for which large changes can occur are the dihedral angles between the phenyl and butadienyl moieties, $\mathrm{C} 11-\mathrm{C} 12-\mathrm{C} 13-\mathrm{C} 18(\theta)$ and $\mathrm{C} 22-\mathrm{C} 12-\mathrm{C} 13-\mathrm{C} 14$ $(\omega)$. Obviously, these angles are of similar magnitude (Table 3). As shown in Figure 4, two minima are found along the $\phi$ coordinate. The point of lowest energy at this grid is situated at $\phi=45^{\circ}$, with $\theta=38.4^{\circ}$ (Table 3), essentially the same geometry as obtained in the free optimization. A second minimum is found at $\phi=165^{\circ}$. Here 1 adopts an extended structure with an s-trans torsion angle about the central single bond. A free optimization of this conformer yielded a geometry with $\phi=159.2^{\circ}$ and $\theta=$ $126.8^{\circ}$ at -616.582390 a.u. $\left(-386911.34 \mathrm{kcal} \mathrm{mol}^{-1}\right)$. Hence, the butadiene part is quite planar, while the phenyl groups are rotated out of the plane by $53^{\circ}$ (Figure 3). The energy at this geometry is $1.08 \mathrm{kcalmol}^{-1}$ higher than at $\phi=48.7^{\circ}$. This implies that, although the calculations indicate that a s-gauche geometry such as found in the solid state is favored indeed, in solution or in the gas phase the compound can also occur in a stretched s-trans geometry. The barrier at $\phi$ $=105^{\circ}$, which has a height of $4.14 \mathrm{kcal} \mathrm{mol}^{-1}$ from the $s$ gauche site, is easily crossed at ambient temperatures. A second maximum occurs at the s-cis geometry of the butadiene fragment $\left(\phi=0^{\circ}\right)$.

There appears to be a delicate balance between planarity of the butadiene subsystem and planarity of the styrene subsystems. At $\phi=0^{\circ}$ the butadiene $\pi$-system is intact, but the energy is high since the phenyl groups are forced to be rotated by some $55^{\circ}$ because of steric interference between the ortho hydrogen atoms. In this context it is noteworthy that in butadiene the energy of the $s$-cis geometry $\left(\phi=0^{\circ}\right)$ is not very different from that of the gauche local minimum. ${ }^{[18,19]}$ In 1 some stabilisation must be absent owing to the relatively large $\theta$. At maximum planarity of the styrene
Table 3. $6-311 \mathrm{G}^{*} / \mathrm{MP} 2$ calculated torsion angles $\theta$ and $\omega$ as well as energies of 2,3-diphenylbutadiene (1) as a function of torsion angle $\phi$.

\begin{tabular}{llll}
\hline$\phi^{[\mathrm{a}]}$ & $\theta^{[\mathrm{b}]}$ & $\omega^{[\mathrm{c}]}$ & $E$ [a.u.] \\
\hline 0 & 56.4 & 51.9 & -616.577043 \\
15 & 49.2 & 43.3 & -616.579999 \\
30 & 43.5 & 39.4 & -616.582762 \\
45 & 38.4 & 37.4 & -616.584059 \\
60 & 34.4 & 36.7 & -616.583606 \\
75 & 32.0 & 37.3 & -616.581725 \\
90 & 31.5 & 39.1 & -616.578882 \\
105 & 151.2 & 150.7 & -616.577466 \\
120 & 143.7 & 142.7 & -616.578775 \\
135 & 138.4 & 135.5 & -616.580662 \\
150 & 131.7 & 130.1 & -616.582118 \\
165 & 123.5 & 124.4 & -616.582279 \\
180 & 113.2 & 115.9 & -616.581056 \\
\hline
\end{tabular}

[a] C11-C12-C22-C21 (see Figure 1). [b] C11-C12-C13-C18. [c] $\mathrm{C} 22-\mathrm{C} 12-\mathrm{C} 13-\mathrm{C} 14$. Note that in contrast to the X-ray data in the calculations $\phi$ was taken as positive.

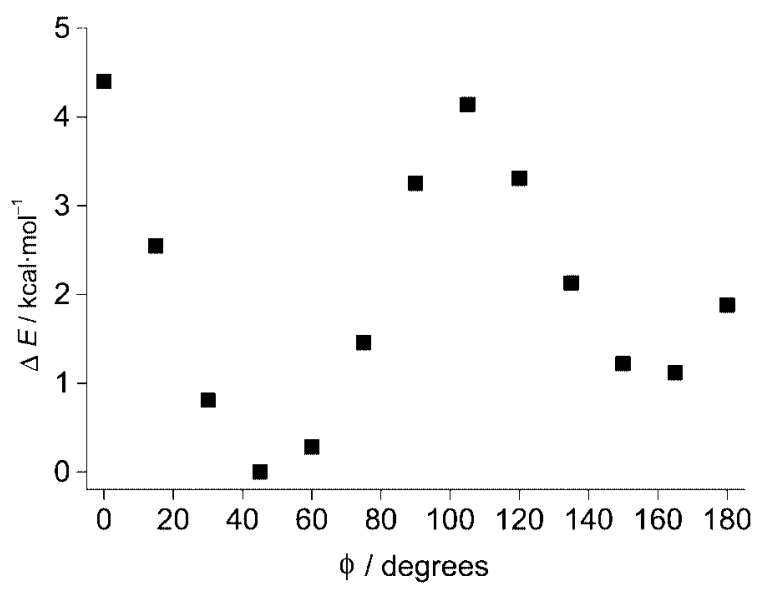

Figure 4. MP2/6-311G* torsional potential along the C12-C22 bond $(\phi)$ in 2,3-diphenylbutadiene $\mathbf{1}$.

parts, i.e. at the smallest values of $\theta$ and $\omega$ which occur from $\phi=60^{\circ}$ to $\phi=120^{\circ}$, the energy is however not at a minimum. Interestingly, the smallest torsion angle $\theta$ is even found at the saddle point at $\phi=105^{\circ}$; the value $180-151.2^{\circ}$ is in agreement with the one typically calculated for styrene, which varies from $0-30^{\circ} .^{[18]}$ The transition state in butadiene is also found near $\phi=105^{\circ} .{ }^{[18,19]}$ It is common knowledge that the energy is high at this point because the $\pi$ bond of butadiene is broken. These observations imply that an (at least partially) intact butadiene $\pi$-system is important for the stability of $\mathbf{1}$, and that a planar styrene $\pi$-system is not of crucial importance. The calculated barrier height is about $2.0 \mathrm{kcal} \mathrm{mol}^{-1}$ lower than the MP2/6-311G** calculated barrier in butadiene. ${ }^{[18]}$ This difference suggests that the stabilizing effect of the phenyl groups on the transition state is only slightly larger than the stabilizing effect of the phenyl groups in the minima.

Hence, according to the MP2/6-311G* calculations neither planarity of the butadiene nor of the styrene conjugation path dominates the structure of 2,3-diphenylbutadiene. 
Two minima are found; the s-gauche structure reflects styrene conjugation, while the s-trans geometry is based on butadiene conjugation. This is also suggested by the calculated bond lengths and the bond length alternation patterns (Table 1). The C12-C13 bond is slightly shorter in the $s$ gauche than in the s-trans geometry, whereas the $\mathrm{C} 12-\mathrm{C} 22$ distance is somewhat shorter in the s-trans minimum.

\section{NBO Deletion Studies}

In order to find out to what extent conjugation and steric factors are responsible for its structure, $\mathbf{1}$ was subjected to a natural bond orbital (NBO) deletion study. ${ }^{[23,24]}$ In this analysis, canonical molecular orbitals are first transformed into a set of localized NBOs comprising core orbitals, lone pairs, Rydberg orbitals, and two center orbitals. ${ }^{[25]}$ The subsequent deletion of weakly occupied NBOs leads to energy changes which can be regarded to represent the loss in delocalization energy. Here, the deletion energy $E_{\text {del }}$ is evaluated as a function of the central butadiene torsion angle $\phi$. To this end, the energy of a particular conformation was calculated upon simultaneous deletion of $\pi^{*}$ and $\sigma^{*}$ NBOs of the butadiene system including the $\mathrm{C} 12-\mathrm{C} 13$ and $\mathrm{C} 22-\mathrm{C} 23$ bonds. This gives the contribution of the idealized Lewis structure $\left(E_{\mathrm{L}}\right)$ to the total energy $\left(E_{\mathrm{tot}}\right)$ and represents a fully localized description. The non-Lewis fraction of the total energy $E_{\mathrm{NL}}$ is given by the difference between the total energy and the Lewis contribution and equals the deletion energy $\left(E_{\mathrm{NL}}=E_{\mathrm{del}}=E_{\mathrm{tot}}-E_{\mathrm{L}}\right)$. This non-Lewis contribution corresponds to the delocalization energy provided that contributions from Rydberg orbitals are negligible and steric repulsions are small. ${ }^{[24]}$ Since the NBO analysis is not feasible with the MP2 method, it was performed at the $\mathrm{SCF} / 6-311 \mathrm{G}^{*}$ level of theory. The SCF/6-311G* torsional potential around $\phi\left(\Delta E_{\text {tot }}\right.$, Figure 5) is similar to the MP2/ 6-311G* curve, albeit that the s-gauche minimum is situated at 60 instead of $45^{\circ}$. The $E_{\text {del }}$ data were set to zero at $\phi=$ $165^{\circ}$ in order to compare them with the total energy $\left(\Delta E_{\mathrm{del}}\right.$; the minimum of the $E_{\mathrm{del}}$ curve is actually situated at $-167.01 \mathrm{kcalmol}^{-1}$, at $\phi=60^{\circ}$ ).

It is evident from Figure 5 that the course of the total energy closely follows the $\Delta E_{\text {del }}$ data. The location of the two minima and the transition state coincide nicely, while energy differences between stationary points do not differ by more than about $1.5 \mathrm{kcalmol}^{-1}$. This makes clear that the conformational behavior of $\mathbf{1}$ is almost entirely governed by delocalization phenomena. Also the observation that the s-gauche minimum has a lower energy than the $s$ trans minimum is a consequence of a different delocalization energy. The good agreement between the $\Delta E_{\text {tot }}$ and $\Delta E_{\text {del }}$ curves show that secondary effects like steric repulsion play only a minor role along the $\phi$ coordinate. Steric crowding was seen to have a possible effect on the $\mathrm{C} 12-\mathrm{C} 13$ and $\mathrm{C} 22-\mathrm{C} 23$ bond lengths in the X-ray structure, but small variations in bond lengths are not expected to have a significant bearing on the delocalization energy.

The rotational dependence of the delocalization and total energy arises from an interplay of a number of interactions.

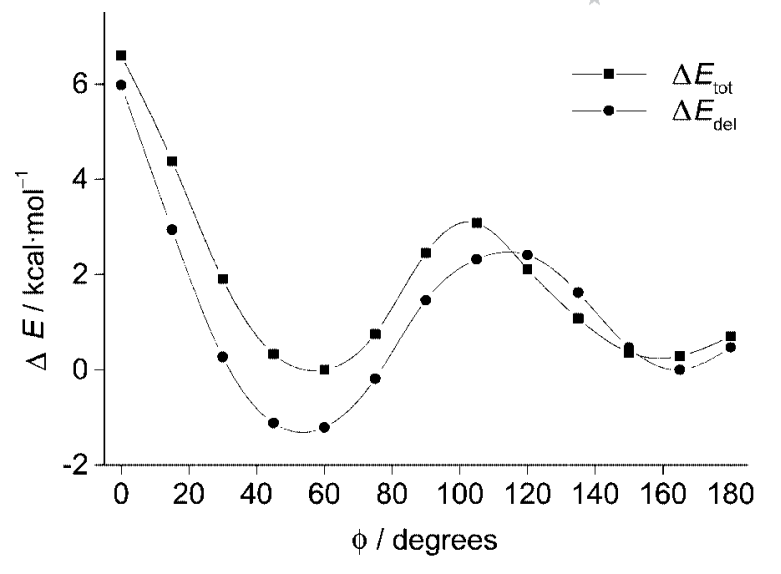

Figure 5. Effect of deletion of the butadiene $\sigma^{*}$ and $\pi^{*}$ NBOs $\left(\Delta E_{\mathrm{del}}\right)$ as a function of $\phi$. Differences in the total SCF/6-311G* energy $\Delta E_{\text {tot }}$ are also given. In order to facilitate comparison with $\Delta E_{\text {tot }}, \Delta E_{\text {del }}$ data were set to zero at $165^{\circ}$. As a consequence, vertical distances between the curves are arbitrary. At minima in the $\Delta E_{\text {del }}$ curve the delocalisation energy is large. Drawn lines are guides to the eye and have no physical significance.

The mutual interactions between the butadiene-type double bonds, interactions between the butadiene double bond and the phenyl groups, delocalization within the $\sigma$-framework, and " $\sigma-\pi$ mixing" (hyperconjugation) all play a role. Inspection of second-order interaction energies in the NBO basis reveals that an important factor in the rotational behaviour of $\mathbf{1}$ is the hyperconjugative interaction in which the $\mathrm{C} 11-$ $\mathrm{C} 12$ (or $\mathrm{C} 21-\mathrm{C} 22$ ) $\pi$-bond functions as donor and the $\mathrm{C} 22-$ $\mathrm{C} 23$ (or C12-C13) $\sigma^{*} \mathrm{NBO}$ functions as acceptor. This interaction is maximal $\left(5.27 \mathrm{kcalmol}^{-1}\right.$ a piece) at $\phi=90^{\circ}$, while it is smaller than $0.5 \mathrm{kcalmol}^{-1}$ at the extremes of $\phi$. It is noteworthy that the hyperconjugation has a opposite nature from that in alkenes, which relies on electron donation from saturated to unsaturated bonds. ${ }^{[26]}$

\section{General Discussion and Conclusions}

From the perspective of the structure of butadiene, which prefers to adopt an $s$-trans conformation around the central single bond, ${ }^{[18,19]}$ the $s$-gauche crystal structure of 2,3-diphenylbutadiene is unexpected. The MP2/6-311G* calculations show that the s-gauche conformation represents one of the two minima along the $\phi$ coordinate, the other one being a structure with an s-trans butadiene geometry. The energy of the latter conformer is slightly higher. The two minima are separated by a barrier at a geometry with a highly twisted butadiene $\pi$-system $\left(\phi=105^{\circ}\right)$. It is noteworthy that only one crystal structure of a related butadiene is available in the literature, that of 2,3-di-tert-butyl-1,3-butadiene. ${ }^{[27]}$ In this compound the torsion angle around the central single bond amounts to $96.62(14)^{\circ}$, which is close to the torsion angle at the transition state in $\mathbf{1}$ (for the gas phase, a similar torsional angle of $101.5^{\circ}$ has been reported $^{[28]}$.

The crystal structure of $\mathbf{1}$ is similar to the electron diffraction structure of [4]dendralene (3,4-dimethylenehexa- 
1,5-diene). This compound adopts a $C_{2}$ geometry with a central torsion angle (compare to $\phi$ in $\mathbf{1}$ ) of $71.7^{\circ}$ and a $\theta$ like torsion angle of $-174.8^{\circ} .^{[16]} \mathrm{Ab}$ initio calculations at various levels of theory give a somewhat larger torsion angle $\phi$ of $73.8-80.2^{\circ}$ and $\theta$ values in the range 172.4 $174.8^{\circ} .^{[16,30]}$ According to the same calculations, a conformer with $\phi$ and $\theta$ angles of 158.4 and $-48.5^{\circ}$, respectively, being reminiscent of the s-trans structure of $\mathbf{1}$, occurs as well. ${ }^{[16]}$ It is $2.1 \mathrm{kcal} \mathrm{mol}^{-1}$ higher in energy than the minimum structure. In $\mathbf{1}$, the preference for the gauche geometry is thus less pronounced. When interpreted in terms of conjugation, this suggests that in the s-gauche structure of $\mathbf{1}$ interaction between the double bonds and the phenyl groups is relatively inefficient. This is rationalized by the fact that stabilization by interactions between olefinic $\pi$ levels, which are of similar energy, will be more favourable than stabilization by an interaction between energetically different phenyl and olefinic $\pi$-levels. It is further noteworthy that in the prevailing structure of the simplest crossconjugated compound, [3]dendralene (3-methylenepenta1,4-diene), there is a slightly twisted anti-butadiene fragment while the third vinyl group is rotated by $40-50^{\circ}$ relative to the butadiene plane. ${ }^{[29,30]}$

By exhibiting small dihedral angles $\theta$ around the phenylbutadiene essential single bonds, the solid state geometry suggests that occurrence of conjugation in the styrene parts is more important than conjugation in the butadiene fragment. The ab initio calculations refine this picture and show that butadiene conjugation can certainly not be neglected. This is indicated by the presence of a minimum with an almost planar butadiene subsystem and large $\theta$ and by the penalty that is paid on breaking the butadiene $\pi$-system in the transition state. According to its structure, $\mathbf{1}$ should thus neither be considered as a $\alpha, \alpha$-bistyryl nor as a 2,3-disubstituted butadiene. The actual situation lies somewhere in between. The NBO deletion studies show that this is predominantly dictated by delocalization effects, and that hyperconjugative interactions also play a role.

\section{Experimental Section}

General: Details of the crystal structure determination can be found elsewhere. ${ }^{[17]}$

Computational Methods: Both MP2 and SCF calculations were performed with GAMESS-UK version 7.0, ${ }^{[31]}$ employing the $6-311 \mathrm{G}^{*}$ basis set. The minima were characterized by a Hessian calculation; no imaginary frequencies were found. NBO deletion studies ${ }^{[24]}$ were conducted with the NBO module implemented in Gaussian 98 ${ }^{[32]}$ on the SCF/6-311G* geometries taken from the GAMESS outputs. Cartesian coordinates of MP2/6-311G* calculated minima of 1 are to be found in the Supporting Information.

Synthesis of 2,3-Diphenyl-1,3-butadiene (1): From the methods available for the synthesis of $1,{ }^{[33-35]}$ we chose the double Wittig reaction of benzil with triphenylmethylphosphonium bromide, ${ }^{[36]}$ albeit with another solvent. Thus, in a nitrogen atmosphere, a suspension of triphenylmethylphosphonium bromide $(37.40 \mathrm{~g}$, $104.7 \mathrm{mmol})$ in THF $(250 \mathrm{~mL})$ was stirred and cooled to $0{ }^{\circ} \mathrm{C}$. In $30 \mathrm{~min} n$-butyllithium in hexanes $(66 \mathrm{~mL}$ of a $1.6 \mathrm{M}$ solution,
$106 \mathrm{mmol}$ ) was added, upon which a clear, orange-red solution was obtained. The temperature of the reaction mixture was gradually allowed to reach room temperature. After $1 \mathrm{~h}$ stirring, a solution of benzil $(10.00 \mathrm{~g}, 47.57 \mathrm{mmol})$ in THF $(70 \mathrm{~mL})$ was added in $30 \mathrm{~min}$. The reaction mixture was refluxed overnight, quenched with water $(250 \mathrm{~mL})$ and extracted with diethyl ether $(3 \times 250 \mathrm{~mL})$. The combined organic layers were dried on magnesium sulfate, filtered and dried under reduced pressure. Crude 1 (16.09 g, purity $<$ $76 \%$ according to GC) was obtained after flash chromatography with chloroform on silica. Consecutive recrystallisations from hexane and ethanol gave $1.5 \mathrm{~g}(15 \%)$ of pure 1 (purity $>99.7 \%$ by GC); m.p. $46^{\circ} \mathrm{C}\left(\right.$ ref. $\left.^{[36]} 45-47^{\circ} \mathrm{C}\right) .{ }^{1} \mathrm{H} \mathrm{NMR}\left(\mathrm{CDCl}_{3}\right): \delta=7.41-$ $7.36(\mathrm{~m}, 4 \mathrm{H}, \mathrm{Ar}-\mathrm{H}), 7.29-7.20(\mathrm{~m}, 6 \mathrm{H}, \mathrm{Ar}-\mathrm{H}), 5.53\left(\mathrm{~d},{ }^{2} J_{\mathrm{H}, \mathrm{H}}=\right.$ $\left.1.65 \mathrm{~Hz}, 2 \mathrm{H},=\mathrm{CH}_{2}\right), 5.30\left(\mathrm{~d},{ }^{2} J_{\mathrm{H}, \mathrm{H}}=1.65 \mathrm{~Hz}, 2 \mathrm{H},=\mathrm{CH}_{2}\right) \mathrm{ppm}$. ${ }^{13} \mathrm{C}$ NMR $\left(\mathrm{CDCl}_{3}\right): \delta=150.0\left(C=\mathrm{CH}_{2}\right), 140.4,128.3(2 \times), 127.7$ (aromatic $\mathrm{C}), 116.5\left(\mathrm{C}=\mathrm{CH}_{2}\right)$ ppm. IR (neat): $\tilde{v}=3032,1608,1574$, 1493, 1443, 1098, 1071, 1029, 902, 774, $705 \mathrm{~cm}^{-1}$. GC-MS: $\mathrm{m} / z=$ $206\left[\mathrm{M}^{+}\right], 191,178,165,152,128,115,102,91,77,51$.

Supporting Information (see also the footnote on the first page of this article): Cartesian coordinates of the MP2/6-311G* s-gauche and $s$-trans geometries of 2,3-diphenylbutadiene.

\section{Acknowledgments}

This work was supported in part (M. L., A. L. S.) by the Nederlandse Organisatie voor Wetenschappelijk Onderzoek, Chemische Wetenschappen (NWO-CW). R. W. A. H. acknowledges financial support from Nederlandse Organisatie voor Wetenschappelijk Onderzoek (NWO), grant 700.53.401. The authors thank NWO/NCF for the use of supercomputer time on TERAS/ASTER, SARA (project number SG-032).

[1] H. Hopf, Angew. Chem. 1984, 96, 947-958.

[2] P. W. Fowler, P. Hansen, G. Caporossi, A. Soncini, Chem. Phys. Lett. 2001, 342, 105-112.

[3] M. R. Bryce, M. A. Coffin, P. J. Skabara, A. J. Moore, A. S. Batsanov, J. A. K. Howard, Chem. Eur. J. 2000, 6, 1955-1962.

[4] J. P. Gisselbrecht, N. N. P. Moonen, C. Boudon, M. Brøndsted Nielsen, F. Diederich, M. Gross, Eur. J. Org. Chem. 2004, 2959-2972.

[5] M. Klokkenburg, M. Lutz, A. L. Spek, J. H. van der Maas, C. A. van Walree, Chem. Eur. J. 2003, 9, 3544-3554.

[6] C. A. van Walree, V. E. M. Kaats-Richters, S. J. Veen, B. Wieczorek, J. H. van der Wiel, B. C. van der Wiel, Eur. J. Org. Chem. 2004, 3046-3056.

[7] K. Itami, Y. Ohashi, J. Yoshida, J. Org. Chem. 2005, 70, 2778 2792.

[8] N. F. Phelan, M. Orchin, J. Chem. Educ. 1968, 45, 633-637.

[9] M. Gholami, R. R. Tykwinski, Chem. Rev. 2006, 106, 49975027.

[10] M. H. van der Veen, M. T. Rispens, H. T. Jonkman, J. C. Hummelen, Adv. Funct. Mater. 2004, 14, 215-223.

[11] R. Baer, D. Neuhauser, J. Am. Chem. Soc. 2002, 124, 42004201.

[12] M. Mizouchi, A. Ikawa, H. Fukutome, J. Am. Chem. Soc. 1995, 117, 3260-3269.

[13] M. Iyoda, S. Sasaki, M. Miura, M. Fukuda, J. Yamauchi, Tetrahedron Lett. 1999, 40, 2807-2810.

[14] N. Tyutyulkov, F. Dietz, K. Müllen, M. Baumgarten, S. Karabunarliev, Chem. Phys. 1994, 189, 83-97.

[15] B. C. van der Wiel, R. M. Williams, C. A. van Walree, Org. Biomol. Chem. 2004, 2, 3432-3433.

[16] P. T. Brain, B. A. Smart, H. E. Robertson, M. J. Davis, D. W. H. Rankin, W. J. Henry, I. Gosney, J. Org. Chem. 1997, 62, 2767-2773. 
[17] M. Lutz, A. L. Spek, B. C. van der Wiel, C. A. van Walree, Acta Crystallogr., Sect. C 2005, 61, o300-0302.

[18] A. Karpfen, C. H. Choi, M. Kertesz, J. Phys. Chem. A 1997, 101, 7426-7433.

[19] M. A. Murcko, H. Castejon, K. B. Wiberg, J. Phys. Chem. 1996, 100, 16162-16168.

[20] J. C. Cochran, K. Hagen, G. Paulen, Q. Shen, S. Tom, M. Traetteberg, C. Wells, J. Mol. Struct. 1997, 413-414, 313-326.

[21] Handbook of Chemistry and Physics, 82nd ed. (Ed.: D. R. Lide), CRC, Boca Raton, 2001, pp. 9-1 to 9-14.

[22] M. Bruschi, M. G. Giuffreda, H. P. Lüthi, ChemPhysChem 2005, 6, 511-519.

[23] M. Bruschi, M. G. Giuffreda, H. P. Lüthi, Chem. Eur. J. 2002, 8, 4216-4227.

[24] M. G. Giuffredda, M. Bruschi, H. P. Lüthi, Chem. Eur. J. 2004, $10,5671-5680$.

[25] A. E. Reed, L. A. Curtiss, F. Weinhold, Chem. Rev. 1988, 88, 899-926.

[26] D. Cappel, S. Tüllmann, A. Krapp, G. Frenking, Angew. Chem. Int. Ed. 2005, 44, 3617-3620.

[27] W. R. Roth, O. Adamczak, R. Breuckmann, H.-W. Lennartz, R. Boese, Chem. Ber. 1991, 124, 2499-2521.

[28] M. Traetteberg, H. Hopf, H. Lipka, R. Haenel, Chem. Ber. 1994, 127, 1459-1467.

[29] A. Almenningen, A. Gatial, D. S. B. Grace, H. Hopf, P. Klaeboe, F. Lehrich, C. J. Nielsen, D. J. Powel, M. Traetteberg, Acta Chem. Scand. Ser. A 1988, 42, 634-650.

[30] M. H. Palmer, J. A. Blair-Fish, P. Sherwood, J. Mol. Struct. 1997, 412, 1-18.
[31] M. F. Guest, I. J. Bush, H. J. J. van Dam, P. Sherwood, J. M. H. Thomas, J. H. van Lenthe, R. W. A. Havenith, J. Kendrick, Mol. Phys. 2005, 103, 719-747.

[32] M. J. Frisch, G. W. Trucks, H. B. Schlegel, G. E. Scuseria, M. A. Robb, J. R. Cheeseman, V. G. Zakrzewski, J. A. Montgomery Jr, R. E. Stratmann, J. C. Burant, S. Dapprich, J. M. Millam, A. D. Daniels, K. N. Kudin, M. C. Strain, O. Farkas, J. Tomasi, V. Barone, M. Cossi, R. Cammi, B. Mennucci, C. Pomelli, C. Adamo, S. Clifford, J. Ochterski, G. A. Petersson, P. Y. Ayala, Q. Cui, K. Morokuma, D. K. Malick, A. D. Rabuck, K. Raghavachari, J. B. Foresman, J. Cioslowski, J. V. Ortiz, A. G. Baboul, B. B. Stefanov, G. Liu, A. Liashenko, P. Piskorz, I. Komaromi, R. Gomperts, R. L. Martin, D. J. Fox, T. Keith, M. A. Al-Laham, C. Y. Peng, A. Nanayakkara, C. Gonzalez, M. Challacombe, P. M. W. Gill, B. Johnson, W. Chen, M. W. Wong, J. L. Andres, C. Gonzalez, M. Head-Gordon, E. S. Replogle, J. A. Pople, Gaussian 98, Version A.7, Gaussian, Inc., Pittsburgh PA, 1998.

[33] A. Hirao, Y. Sakano, K. Takenaka, S. Nakahama, Macromolecules 1998, 31, 9141-9145.

[34] R. A. Wagner, U. H. Brinker, Synthesis 2001, 376-378.

[35] T. Yamamoto, T. Yasuda, K. Kobayashi, I. Yamaguchi, T. Koizumi, D. Ishii, M. Nakagawa, Y. Mashiko, N. Shimizu, Bull. Chem. Soc. Jpn. 2006, 79, 498-500.

[36] Æ. de Groot, B. Evenhuis, H. Wynberg, J. Org. Chem. 1968 , $33,2214-2217$.

Received: May 7, 2007

Published Online: July 25, 2007 